\title{
L-ARGININE, PROSTAGLANDIN, AND WHITE CELL FILTRATION EQUALLY IMPROVE MYOCARDIAL PROTECTION IN STRESSED NEONATAL HEARTS
}

Michael T. Kronon, MD

Bradley S. Allen, MD

Ari Halldorsson, MD

Shaikh Rahman, $\mathrm{PhD}$

Tingrong Wang, MD

Michel Ilbawi, MD
Objectives: L-Arginine may improve cardioplegic protection by increasing nitric oxide production. However, L-arginine may also be detrimental because it generates the free radical peroxynitrite. It would, therefore, be advantageous if the benefits of $L$-arginine could be achieved by another means. Methods: Twenty neonatal piglets underwent 60 minutes of ventilator hypoxia (inspired oxygen fraction 8\%-10\%) followed by 20 minutes of ischemia on cardiopulmonary bypass (stress) and were then protected for $\mathbf{7 0}$ minutes with multiple doses of blood cardioplegic solution. In 5 piglets (group 1), the cardioplegic solution was not modified; in 5 (group 2), low-dose L-arginine (4 mmol/L) was added; in 5 (group 3), prostaglandin $\mathrm{E}_{1}$ (alprostadil, $4 \mu \mathrm{g} / \mathrm{L}$ ) was added; and in 5 (group 4), the cardioplegic solution was passed through a leukodepleting filter. Myocardial function was assessed by pressure volume loops and expressed as percentage of control, and coronary vascular resistance was measured with each cardioplegic infusion. Results: Unmodified blood cardioplegic solution (group 1) was unable to protect the severely stressed myocardium, resulting in depressed systolic function $(39 \% \pm$ $1 \%)$ and preload recruitable stroke work $(40 \% \pm 1 \%)$, increased diastolic stiffness $(239 \% \pm 3 \%)$, and high conjugated diene production, myeloperoxidase activity, and coronary vascular resistance. In contrast, cardioplegic solutions modified with L-arginine, prostaglandin $\mathrm{E}_{1}$, or leukodepletion, resuscitated the stressed myocardium, resulting in complete return of systolic function $(100 \%$ vs $101 \%$ vs $101 \% ; P<.001$ vs group 1) and preload recruitable stroke work (100\% vs $101 \%$ vs $101 \%$; $P<.001$ vs group 1), minimal increase in diastolic stiffness $(160 \%$ vs $162 \%$ vs $160 \% ; P<.001$ vs group 1 ), and lowered conjugated diene production, myeloperoxidase activity, and coronary vascular resistance ( $P<.001$ vs group 1 for each). Conclusions: (1) Unmodified blood cardioplegic solution is unable to protect the severely stressed myocardium. (2) L-Arginine, prostaglandin $\mathrm{E}_{1}$, and leukocyte filtration all improve myocardial protection equally and appear to work by limiting a white blood cell-mediated injury. This reduces oxygen-derived free radical formation, maintains vascular function, and restores functional recovery. Since L-arginine may be detrimental, surgeons should consider using prostaglandin $\mathrm{E}_{1}$ and/or a leukocyte filter instead.

(J Thorac Cardiovasc Surg 1999;118:665-73)
From the Division of Cardiovascular Surgery, The Heart Institute for Children, Hope Children's Hospital, Oak Lawn, Ill.

M.T.K. is supported in part by the Pillsbury Fellowship.

Read at the Twenty-fourth Annual Meeting of The Western Thoracic Surgical Association, Whistler, British Columbia, June 24-27, 1998.

Received for publication July 1, 1998; revisions requested Aug 20, 1998; revisions received July 7, 1999; accepted for publication July 13, 1999.
Address for reprints: Bradley S. Allen, MD, The Heart Institute for Children, Hope Children's Hospital, 4440 West 95th St, Oak Lawn, IL 60453.

Copyright @ 1999 by Mosby, Inc.

$0022-5223 / 99 \$ 8.00+0 \quad \mathbf{1 2} / \mathbf{6} / \mathbf{1 0 1 4 1 8}$ 
$A$ t lower concentrations, L-arginine improves myocardial protection by increasing nitric oxide production. ${ }^{1-5}$ However, at higher concentrations, nitric oxide is detrimental because of overproduction of the toxic oxygen radical peroxynitrite..$^{2,5-8}$ It would therefore be advantageous if the beneficial effects of L-arginine (nitric oxide) could be achieved by another method since the optimum dose of L-arginine, as well as whether nitric oxide production or inhibition is desired, varies depending on several factors. White blood cell (WBC) filters have been shown to reduce the reperfusion injury, and because one of the actions of nitric oxide is to prevent WBC adherence, leukodepleting the cardioplegic solution should have a similar effect. ${ }^{9-11}$ Nitric oxide, however, also promotes vasodilation, as well as decreasing platelet adherence; thus a WBC filter does not completely mimic its actions. Prostaglandins are secreted by vascular endothelial cells and may be one of the mediators by which nitric oxide works. ${ }^{7,12-14}$ Prostaglandins promote vasorelaxation, as well as preventing WBC and platelet adherence, and therefore more closely mimic the actions of nitric oxide. By investigating cardioplegic solutions with and without L-arginine, leukodepleted, and supplemented with prostaglandin $\mathrm{E}_{1}\left(\mathrm{PGE}_{1}\right.$, alprostadil), this study aims (1) to elucidate whether the primary beneficial effect of nitric oxide is vasodilatation, prevention of a WBC-mediated injury, or both, and (2) to provide an alternative approach to L-arginine for improving myocardial protection.

\section{Materials and methods}

Twenty neonatal (5-18 days old) piglets (3.5-5 kg) were premedicated with ketamine $(40 \mathrm{mg} / \mathrm{kg})$ intramuscularly and anesthetized with phenobarbital $(30 \mathrm{mg} / \mathrm{kg})$ intraperitoneally, followed by $5 \mathrm{mg} / \mathrm{kg}$ intravenously each hour. The lungs were ventilated via a tracheotomy with a volume ventilator (Servo 900B, Siemens/Elema, Solna, Sweden). All animals received humane care in compliance with the "Principles of Laboratory Animal Care," formulated by the National Society for Medical Research, and the "Guide for the Care and Use of Laboratory Animals" prepared by the Institute of Laboratory Animal Resources, National Research Council, and published by the National Academy Press, revised 1996. The experimental preparation, including cannulation for bypass and blood sample procurement, is comparable to that previously described. ${ }^{15,16}$

\section{Experimental protocols}

Hypoxic-ischemic stress. Twenty piglets underwent a hypoxic-ischemic stress as previously described by lowering the fraction of inspired oxygen to $8 \%$ to $10 \%$ for 60 minutes (ventilator hypoxia), followed by cardiopulmonary bypass at an inspired oxygen fraction of $100 \%$ for 5 minutes (reoxygenation), and finally clamping the aorta for 20 minutes at $37^{\circ} \mathrm{C}$ (normothermic ischemia). ${ }^{5}$ Piglets then underwent 70 minutes of cardioplegic arrest according to the protocol described below.

Administration of cardioplegic solution. Cardioplegic solutions (CAPS Service, Research Medical Inc, Salt Lake City, Utah) are shown in Tables I and II. After the 20-minute normothermic-ischemic insult (see above), piglets underwent 70 minutes of cardioplegic arrest. The protocol, previously described, consisted of 5 minutes of warm $\left(37^{\circ} \mathrm{C}\right)$ induction (Table I) followed by 4 minutes of cold multidose cardioplegia (Table II), a 2-minute cold multidose infusion every 20 minutes, and a 4 -minute warm $\left(37^{\circ} \mathrm{C}\right)$ cardioplegic reperfusate ("hot shot") before aortic unclamping. ${ }^{5}$ Cardioplegic solution was always infused at a continuously measured aortic root pressure of 40 to $50 \mathrm{~mm} \mathrm{Hg}$. All piglets were weaned from cardiopulmonary bypass with no inotropic support 30 minutes after aortic unclamping. Final functional and biochemical measurements were made 30 minutes after arterial blood gas, $\mathrm{Ca}^{2+}$, and $\mathrm{K}^{+}$levels were normalized.

Experimental groups. Piglets were divided into 4 groups on the basis of the composition of the cardioplegic solution.

Unmodified blood cardioplegic solution (group 1). In 5 piglets, the blood cardioplegic solution was not enriched with L-arginine or $\mathrm{PGE}_{1}$ or passed through a leukocyte filter.

L-Arginine (group 2). In 5 piglets, the cardioplegic solution was enriched with L-arginine $(4 \mathrm{mmol} / \mathrm{L})$.

Prostaglandin (group 3). In 5 piglets, the cardioplegic solution was supplemented with $\mathrm{PGE}_{1}$ (alprostadil, $4 \mu \mathrm{g} / \mathrm{L}$ ).

$W B C$ filter (group 4). In the final 5 piglets, the cardioplegic solution was passed through a Pall BC-1 leukocyte depleting filter (Pall Corp, G1en Cove, NY) before administration.

Myocardial oxygen consumption. After cardioplegic arrest, blood was obtained at 1-minute intervals from the cardioplegia line and coronary sinus over the 5 minutes of warm cardioplegic induction, and myocardial oxygen consumption was calculated as previously described. ${ }^{17}$ The cumulative 5minute myocardial oxygen consumption was determined by the sum of the individual 1-minute values and expressed per $100 \mathrm{~g}$ of heart tissue.

Myocardial performance. Left ventricular (LV) pressure and conductance catheter signals were amplified and digitized to inscribe LV pressure volume loops, the end-systolic and end-diastolic pressure volume relationship, and preload recruitable stroke work, analyzed as previously described. ${ }^{5,15-18}$ Measurements were made before hypoxia (baseline) and 30 minutes after cardiopulmonary bypass was discontinued. Functional measurements are expressed as absolute values as well as percent recovery of baseline values, with each piglet acting as its own control. After final hemodynamic measurements, all piglets were placed back on bypass and hearts were arrested with cold $\left(4^{\circ} \mathrm{C}\right)$ blood cardioplegic solution. Transmural LV biopsy specimens were obtained, as previously described, for biochemical analysis and myocardial water.

Physiologic measurements. Coronary vascular resistance (CVR) was determined during each cardioplegic infusion by measuring coronary sinus pressure and cardioplegic flow 
Table I. Warm blood cardioplegic solution

\begin{tabular}{|c|c|c|c|}
\hline Cardioplegia additive & $\begin{array}{l}\text { Volume added } \\
\qquad(m L)\end{array}$ & Component modified & $\begin{array}{c}\text { Concentration } \\
\text { delivered }\end{array}$ \\
\hline $\mathrm{KCl}(2 \mathrm{mEq} / \mathrm{mL})$ & 10 & $\mathrm{~K}^{+}$ & $8-10 \mathrm{mEq} / \mathrm{L}$ \\
\hline THAM (0.3 mol/L) & 225 & $\mathrm{pH}$ & $\mathrm{pH} 7.5-7.7$ \\
\hline CPD & 225 & $\mathrm{Ca}^{2+}$ & $0.2-0.3 \mathrm{mmol} / \mathrm{L}$ \\
\hline Aspartate/glutamate & 250 & Substrate & $13 \mathrm{mmol} / \mathrm{L}$ each \\
\hline $\mathrm{D}_{50} \mathrm{~W}$ & 40 & Glucose & $<400 \mathrm{mg} / \mathrm{dL}$ \\
\hline $\mathrm{D}_{5} \mathrm{~W}$ & 200 & Osmolarity & $380-400$ mOsm \\
\hline L-Arginine ${ }^{\dagger}$ & 50 & Nitric oxide & $4 \mathrm{mmol} / \mathrm{L}$ (group 2) \\
\hline $\mathrm{PGE}_{1}^{\ddagger}(500 \mu \mathrm{g} / \mathrm{mL})$ & .04 & Vasodilator WBC inhibitor & $4 \mu \mathrm{g} / \mathrm{L}$ \\
\hline
\end{tabular}

THAM, Tromethamine; $C P D$, citrate-phosphate-dextrose; $D 50 \mathrm{~W}, 50 \%$ dextrose in water; $D 5 \mathrm{~W}, 5 \%$ dextrose in water; $P G E 1$, prostaglandin $\mathrm{E}_{1}$.

"When mixed in a 4:1 ratio with blood.

In group 2 piglets, $20 \mathrm{mmol}$ of $\mathrm{L}$-arginine was mixed in $50 \mathrm{~mL}$ of $\mathrm{D}_{5} \mathrm{~W}$ before being added to the cardioplegic solution.

Added in group 3 piglets only.

Table II. Cold multidose blood cardioplegic solution

\begin{tabular}{|c|c|c|c|}
\hline Cardioplegia additive & $\begin{array}{l}\text { Volume added } \\
\qquad(m L)\end{array}$ & Component modified & $\begin{array}{c}\text { Concentration } \\
\text { delivered }^{*}\end{array}$ \\
\hline $\mathrm{KCl}(2 \mathrm{mEq} / \mathrm{mL})$ & 10 & $\mathrm{~K}^{+}$ & $8-10 \mathrm{mEq} / \mathrm{L}$ \\
\hline THAM (0.3 mol/L) & 200 & $\mathrm{pH}$ & $\mathrm{pH} 7.6-7.8$ \\
\hline CPD & 50 & $\mathrm{Ca}^{2+}$ & $0.5-0.6 \mathrm{mmol} / \mathrm{L}$ \\
\hline $\mathrm{D}_{5} \mathrm{~W} 1 / 4 \mathrm{NS}$ & 550 & Osmolarity & 340-360 mOsm \\
\hline L-Arginine ${ }^{\dagger}$ & 50 & Nitric oxide & $4 \mathrm{mmol} / \mathrm{L}$ \\
\hline $\mathrm{PGE}_{1}^{\ddagger}(500 \mu \mathrm{g} / \mathrm{mL})$ & .035 & Vasodilator WBC inhibitor & $4 \mu \mathrm{g} / \mathrm{L}$ \\
\hline
\end{tabular}

THAM, Tromethamine; $C P D$, citrate-phosphate-dextrose; $D 5 W, 5 \%$ dextrose in water; $N S$, normal saline solution; $P G E 1$, prostaglandin $\mathrm{E}_{1}$.

When mixed in a 4:1 ratio with blood.

In group 2 piglets, $17 \mathrm{mmol}$ of L-arginine was mixed in $50 \mathrm{~mL}$ of $\mathrm{D}_{5} \mathrm{~W}$ before being added to the cardioplegic solution.

Added in group 3 piglets only.

once a constant infusion rate with an aortic root pressure between 40 and $50 \mathrm{~mm} \mathrm{Hg}$ was achieved. CVR was calculated as previously described and expressed as dynes $\cdot \mathrm{sec} \cdot \mathrm{cm}^{-5} \cdot 15,16$

\section{Biochemical analysis}

Production of conjugated dienes. Blood samples were obtained from the cardioplegia line and coronary sinus 1 and 5 minutes after the start of warm cardioplegia induction, and myocardial conjugated dienes were assessed as previously described. ${ }^{5}$ Production of conjugated diene was expressed per 100 gm heart tissue by weighing the left ventricle at the conclusion of the experiment.

Adenosine pool and myeloperoxidase activity. The adenosine pool and quantitative myeloperoxidase activity were determined as described previously., ${ }^{5,11,15}$ Adenosine triphosphate (ATP) levels are expressed as micrograms per gram of dry tissue and myeloperoxidase activity as the change in optical density per minute per milligram of tissue protein $(\Delta \mathrm{OD} / \mathrm{min} / \mathrm{mg}$ protein).

Antioxidant reserve capacity. Myocardial antioxidant reserve capacity was determined as described previously by exposing the tissue to a $4 \mathrm{mmol} / \mathrm{L}$ concentration of t-butylhydroperoxide and measuring the production of malondialdehyde. ${ }^{5,19}$ Antioxidant reserve capacity is expressed as malondialdehyde production in nanomoles per gram protein of heart tissue. The greater the production of malondialdehyde to the oxidant stress (t-butylhydroperoxide), the lower the levels of endogenous tissue antioxidants (lower antioxidant reserve capacity), indicating prior exposure of the myocardial tissue to oxygen-derived free radicals during reperfusion.

Myocardial water. The percent myocardial water was calculated as previously described by placing ventricular samples in preweighed vials and drying to a constant weight at a temperature of $85^{\circ} \mathrm{C} .^{5}$

Statistics. Data were analyzed with JMP V2.0 software (SAS Institute, Inc, Cary, NC) on a Macintosh IIVX computer (Apple Inc, Cupertino, Calif). The paired Student $t$ test and 1-way analysis of variance were used for comparison of variables among experimental groups. If the analysis of variance revealed a significant interaction, pair-wise tests of individual group means were compared by means of multiple comparisons (Tukey's test) using a level of significance of $P<.05, P$ $<.01$, and $P<.001$. Group data are expressed as mean \pm standard error of the mean.

\section{Results}

There was no significant difference $(P>.2)$ between groups for baseline (prehypoxic) values of LV contrac- 
Table III. LV function

\begin{tabular}{|c|c|c|c|c|c|c|c|c|}
\hline \multirow[b]{2}{*}{ Group } & \multicolumn{3}{|c|}{ End-systolic elastance } & \multicolumn{2}{|c|}{ Diastolic compliance } & \multicolumn{3}{|c|}{ Preload recruitable stroke work } \\
\hline & $\begin{array}{c}\chi \\
\text { Intercept }\end{array}$ & Slope ${ }^{*}$ & $\begin{array}{c}\% \\
\text { Recovery }\end{array}$ & $\begin{array}{c}\beta \\
\text { Coefficient }\end{array}$ & $\begin{array}{l}\% \text { Control } \\
\text { stiffness }\end{array}$ & $\begin{array}{c}\chi \\
\text { Intercept }\end{array}$ & Slope $e^{\dagger}$ & $\begin{array}{c}\% \\
\text { Recovery }\end{array}$ \\
\hline \multicolumn{9}{|c|}{$\begin{array}{l}\text { Unmodified blood } \\
\text { cardioplegia (group 1) }\end{array}$} \\
\hline Baseline & $6.5 \pm 0.1$ & $34 \pm 2$ & - & $0.04 \pm 0.01$ & - & $10.6 \pm 0.3$ & $66 \pm 3$ & - \\
\hline Postbypass & $6.7 \pm 0.2$ & $14 \pm 2$ & $41 \% \pm 2 \%$ & $0.1 \pm 0.02$ & $267 \% \pm 7 \%$ & $10.5 \pm 0.1$ & $26 \pm 3$ & $39 \% \pm 2 \%$ \\
\hline \multicolumn{9}{|c|}{ L-Arginine (group 2) } \\
\hline Baseline & $6.3 \pm 0.2$ & $36 \pm 1$ & - & $0.05 \pm 0.02$ & - & $10.8 \pm 0.1$ & $69 \pm 3$ & - \\
\hline Postbypass & $6.5 \pm 0.1$ & $36 \pm 2$ & $100 \% \pm 2 \%$ & $0.08 \pm 0.01$ & $160 \% \pm 4 \%$ & $10.7 \pm 0.3$ & $69 \pm 2$ & $100 \% \pm 2 \%$ \\
\hline \multicolumn{9}{|c|}{$\mathrm{PGE}_{1}$ (group 3) } \\
\hline Baseline & $6.6 \pm 0.2$ & $38 \pm 2$ & - & $0.05 \pm 0.01$ & - & $10.3 \pm 0.3$ & $65 \pm 2$ & - \\
\hline Postbypass & $6.8 \pm 0.2$ & $39 \pm 1$ & $101 \% \pm 1 \%$ & $0.08 \pm 0.02$ & $161 \% \pm 4 \%$ & $10.5 \pm 0.1$ & $66 \pm 2$ & $101 \% \pm 1 \%$ \\
\hline \multicolumn{9}{|c|}{ WBC filter (group 3) } \\
\hline Baseline & $6.4 \pm 0.1$ & $37 \pm 1$ & - & $0.05 \pm 0.02$ & - & $10.3 \pm 0.1$ & $65 \pm 2$ & - \\
\hline Postbypass & $6.7 \pm 0.2$ & $38 \pm 1$ & $\begin{array}{c}101 \% \pm 2 \% \\
\mathrm{~F}=558 \\
P<.001\end{array}$ & $0.08 \pm 0.01$ & $\begin{array}{c}162 \% \pm 4 \% \\
\mathrm{~F}=250 \\
P<.001\end{array}$ & $10.5 \pm 0.3$ & $65 \pm 1$ & $\begin{array}{c}101 \% \pm 2 \% \\
\mathrm{~F}=575 \\
P<.001\end{array}$ \\
\hline
\end{tabular}

$\chi$ Intercepts expressed in $\mathrm{mL}$.

*End-systolic elastance slope expressed in $\mathrm{mm} \mathrm{Hg} / \mathrm{mL}$.

†Preload recruitable stroke work slope expressed as $\left[\int(\mathrm{mm} \mathrm{Hg} \cdot \mathrm{mL}) / \mathrm{mL}\right]$.

$\stackrel{\dagger}{\dagger}<.001$ vs groups 2,3 , and 4 .

tility, diastolic compliance, or preload recruitable stroke work. All piglets tolerated 60 minutes of hypoxia with stable hemodynamics.

Hemodynamic and physiologic measurements. Results are depicted in Table III and Figs 1 to 4 . There was no significant change or difference $(P>.2)$ in the $\mathrm{X}$-axis intercept for end-systolic elastance or preload recruitable stoke work between prebypass (baseline) and postbypass values in any experimental group. Therefore, the change in the slope of end-systolic elastance and preload recruitable stroke work can be interpreted to express variability in the contractile state of the myocardium compared with baseline values. This allows the change in slope to be expressed as a percentage of baseline with each piglet acting as its own control. Unmodified blood cardioplegic solution (group 1) was unable to resuscitate the severely stressed (hypoxic-ischemic) myocardium, resulting in decreased postbypass systolic contractility, markedly increased diastolic stiffness, and reduced preload recruitable stroke work. In contrast, cardioplegic solution supplemented with L-arginine (group 2), $\mathrm{PGE}_{1}$ (group 3 ), or passed through a WBC filter (group 4) resuscitated and protected the severely stressed myocardium, resulting in complete return of systolic function and preloaded recruitable stroke work, and minimally increased diastolic stiffness. These values (groups 2-4) were not statistically different $(P>.2)$ from each other, indicating similar beneficial effects for all 3 interven- tions with regard to myocardial functional recovery. The Pall BC-1 leukodepleting filter was extremely efficient at lowering the concentrations of WBCs $(13.2 \pm$ 0.4 prefilter vs $0.3 \pm 0.1$ postfilter) and neutrophils ( 7.5 \pm 0.3 prefilter vs $0.2 \pm 0.1$ postfilter), but only mildly reduced the platelet count $(234 \pm 12$ prefilter vs $139 \pm$ 10 postfilter).

Tissue studies. Results are summarized in Table IV. Unmodified blood cardioplegic solution caused a significant oxygen-derived free radical-mediated reperfusion injury documented by the high production of conjugated dienes during cardioplegic induction (reperfusion) and the decreased tissue antioxidant reserve capacity (high malondialdehyde production). The myeloperoxidase activity was increased, suggesting that this injury may be mediated by WBCs, and the ATP/ADP ratio, which is an indirect measurement of mitochondrial function, was decreased. In contrast, the production of oxygen-derived free radicals was equally prevented (lower conjugated dienes and higher antioxidant reserve capacity) by supplementing the cardioplegic solution with L-arginine or $\mathrm{PGE}_{1}$ or by passing it through a WBC filter. The myeloperoxidase activity was also equally decreased in these 3 groups. Reducing oxygen-derived free radical production prevented mitochondrial damage (preservation of the ATP/ADP ratio), allowing the mitochondria to replenish ATP to normal levels and resulting in a significantly higher myocardial oxygen consumption during warm cardioplegic induc- 

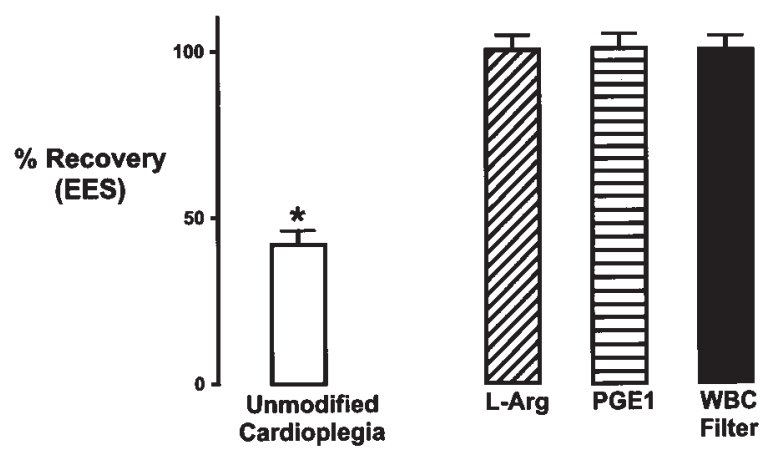

Modified Cardioplegia

Fig 1. Postbypass LV contractile function (hypoxic-ischemic hearts). Recovery of LV systolic function as measured by endsystolic elastance (EES) and expressed as percentage of control (baseline). Note: Exposing the heart to hypoxia and ischemia produces such a severe stress that aspartate-glutamate blood cardioplegic solution is unable to fully resuscitate the heart. In contrast, cardioplegic solution enriched with L-arginine, $\mathrm{PGE}_{1}$, or passed through a WBC filter is able to fully resuscitate the hypoxic myocardium, resulting in complete return of systolic function. $* P<0.001$ (mean \pm standard error).

tion. Myocardial water, which is an indirect measurement of cellular injury, was also lower and equivalent in these groups (groups 2-4).

\section{Discussion}

L-Arginine improves myocardial protection through its production of nitric oxide, which prevents $\mathrm{WBC}$ and platelet adherence and induces vasorelaxation. ${ }^{1-4}$ However, L-arginine also produces the toxic oxygenderived free radical peroxynitrite and thus under certain conditions it can be detrimental. ${ }^{5,6,20}$ Because it may be difficult to determine under what conditions and at what dose L-arginine may be harmful, an alternative approach that achieves the same beneficial effects would be advantageous. Prostaglandins are released by endothelial cells and, like nitric oxide, prevent WBC adherence and vasodilate coronary vessels. ${ }^{7,12-14,21}$ Whereas L-arginine needs to be converted to nitric oxide by the intact endothelial cell, prostaglandins act directly. Prostaglandins could therefore be superior in the presence of damaged endothelium. $\mathrm{PGE}_{1}$ does not produce oxygen radicals at higher doses, and this study used a concentration of $\mathrm{PGE}_{1}$ that results in a low systemic dose $\left(0.03-0.04 \mu \mathrm{g} \cdot \mathrm{kg}^{-1} \cdot \mathrm{min}^{-1}\right)$. Systemic doses up to 5 to 10 times this dose are routinely used clinically without problems. ${ }^{21} \mathrm{~A}$ WBC filter does not act directly on the vascular endothelium or cause vasodilatation. It was therefore used in 1 group of

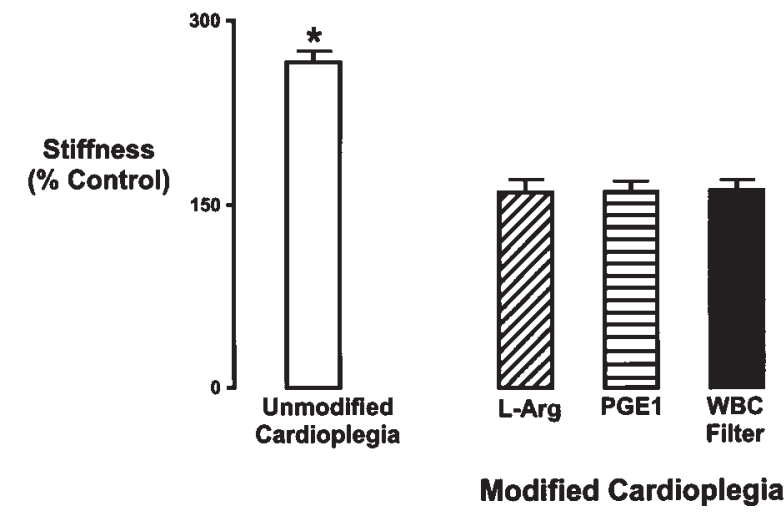

Fig 2. Postbypass LV diastolic compliance as measured by the end-diastolic pressure volume relationship and expressed as percentage of stiffness compared to control (baseline). Note: There is a marked increase in diastolic stiffness in hearts given blood cardioplegic solution alone. Conversely, enriching the cardioplegic solution with L-arginine, $\mathrm{PGE}_{1}$, or pumping it through a WBC filter allowed for cellular repair of the hypoxic ischemia injury, improving diastolic compliance. $* P<0.001$ (mean \pm standard error).

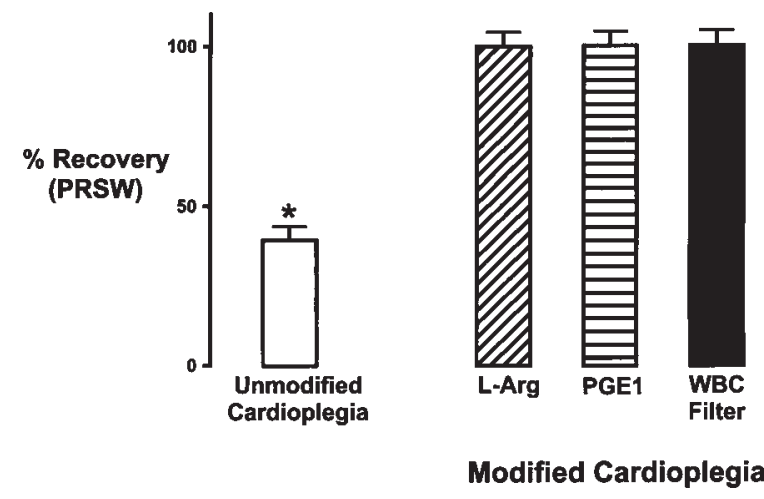

Fig 3. Postbypass overall myocardial function (hypoxicischemic hearts). Recovery of overall myocardial function as measured by preload recruitable stroke work $(P R S W)$ and expressed as a percentage of control (baseline). $* P<0.001$ (mean \pm standard error).

piglets to allow quantification of the contribution of WBCs in mediating the reperfusion injury independent of other factors (ie, vasodilation).

This study used both an ischemic and hypoxic stress because each increases WBC adherence. This protocol thus allowed the methods of protection to be tested in vulnerable hearts. Furthermore, compared with hypoxia alone, the combination of hypoxia and ischemia may more closely resemble the condition of the cyanotic 


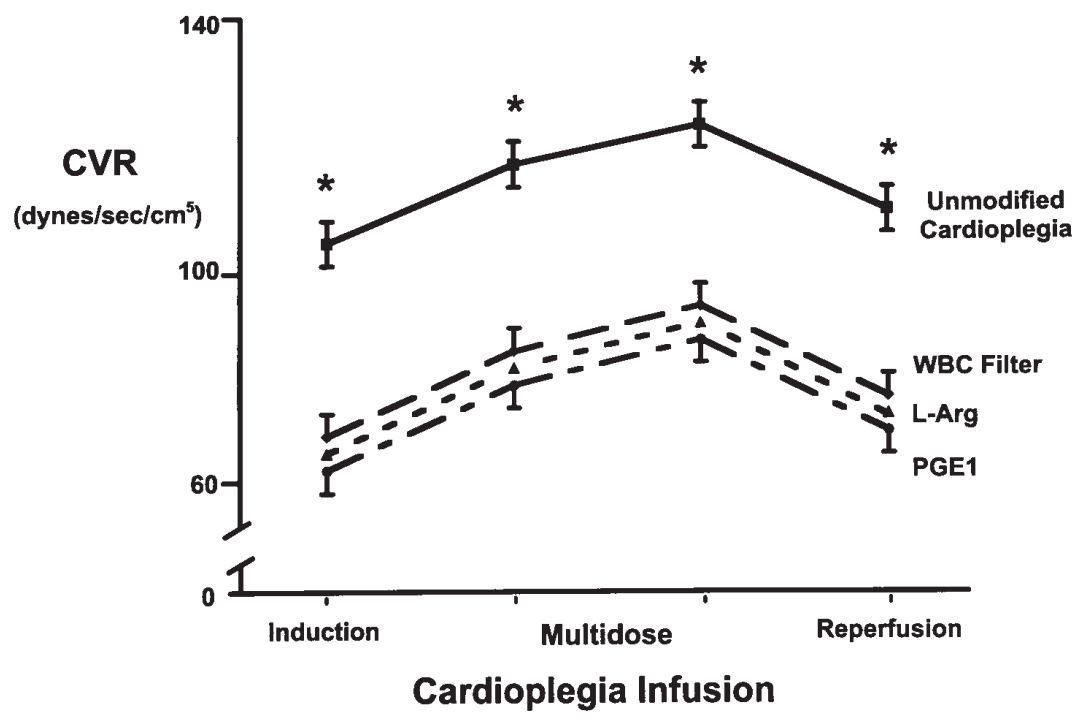

Fig 4. Coronary vascular resistance $(C V R)$ measured during cardioplegic infusions once the flow and cardioplegic pressures were stable. Note: Because a WBC filter does not cause vasodilation, the lower CVR in groups 2 to 4 must be due to preservation of vascular function and not vasodilation. This also implies that L-arginine and $\mathrm{PGE}_{1}$ prevent vascular damage primarily by inhibition of a WBC-mediated injury. ${ }^{*} P<0.001$ (mean \pm standard error).

Table IV. Myocardial oxygen consumption and biochemical results

\begin{tabular}{|c|c|c|c|c|c|c|c|c|}
\hline \multirow[b]{2}{*}{ Group } & \multirow{2}{*}{$\begin{array}{c}\mathrm{MVO}_{2}{ }^{*} \\
(\mathrm{~mL} / 100 \mathrm{gm} / \\
5 \mathrm{~min})\end{array}$} & \multicolumn{2}{|c|}{$\begin{array}{c}C D \text { production }{ }^{*} \\
(O D / \mathrm{mL} / 100 \mathrm{gm} / \mathrm{min})\end{array}$} & \multirow{2}{*}{$\begin{array}{c}A R C^{\dagger} \\
\text { (MDA nmol/ } \\
\text { g protein) }\end{array}$} & \multirow{2}{*}{$\begin{array}{c}A T P \\
(\mu g / g \\
d r y w t)\end{array}$} & \multirow{2}{*}{$\begin{array}{l}\text { ATP/ADP } \\
\text { ratio }\end{array}$} & \multirow{2}{*}{$\begin{array}{c}\text { Myocardial } \\
\text { water } \\
(\%)\end{array}$} & \multirow{2}{*}{$\begin{array}{c}M P O \\
(\triangle O D / \mathrm{min} / \\
\text { mg protein })\end{array}$} \\
\hline & & $1 \mathrm{~min}$ & $5 \mathrm{~min}$ & & & & & \\
\hline $\begin{array}{l}\text { Unmodified blood } \\
\text { cardioplegia (group 1) }\end{array}$ & $6.7 \pm 0.3^{\ddagger}$ & $72 \pm 2$ & $74 \pm 2^{\ddagger}$ & $1216 \pm 26^{\ddagger}$ & $10.8 \pm 0.6^{\ddagger}$ & $2.0 \pm 0.3^{\ddagger}$ & $80.7 \pm 0.2^{\ddagger}$ & $1.6 \pm 0.1^{\ddagger}$ \\
\hline L-Arginine (group 2) & $10.2 \pm 0.2$ & $20 \pm 2$ & $21 \pm 2$ & $858 \pm 28$ & $16.1 \pm 0.4$ & $3.8 \pm 0.3$ & $79.7 \pm 0.3$ & $0.9 \pm 0.1$ \\
\hline $\mathrm{PGE}_{1}$ (group 3) & $10.3 \pm 0.1$ & $21 \pm 1$ & $23 \pm 2$ & $854 \pm 19$ & $16.2 \pm 0.3$ & $3.6 \pm 0.3$ & $79.7 \pm 0.2$ & $0.8 \pm 0.1$ \\
\hline WBC filter (group 4) & $\begin{array}{c}10.4 \pm 0.2 \\
\mathrm{~F}=144 \\
P<.001\end{array}$ & $\begin{array}{c}21 \pm 1 \\
\mathrm{~F}=518 \\
P<.001\end{array}$ & $\begin{array}{c}23 \pm 2 \\
\mathrm{~F}=537 \\
P<.001\end{array}$ & $\begin{array}{l}878 \pm 21 \\
\mathrm{~F}=110 \\
P<.001\end{array}$ & $\begin{array}{c}16.3 \pm 0.3 \\
\mathrm{~F}=75.8 \\
P<.001\end{array}$ & $\begin{array}{l}3.7 \pm 0.4 \\
\mathrm{~F}=16.6 \\
P<.001\end{array}$ & $\begin{array}{l}79.6 \pm 0.3 \\
\mathrm{~F}=10.3 \\
P<.001\end{array}$ & $\begin{array}{l}0.9 \pm 0.1 \\
\mathrm{~F}=15.6 \\
P<.001\end{array}$ \\
\hline
\end{tabular}

MVO2, Myocardial oxygen consumption; $C D$, conjugated diene; OD, optical density; $A R C$, antioxidant reserve capacity; $M D A$, malondialdehyde; $A T P$, adenosine triphosphate; $A D P$, adenosine diphosphate; $M P O$, myeloperoxidase.

"During cardioplegia induction (reperfusion).

MDA production at $4 \mathrm{mmol} / \mathrm{L}$ t-butylhydroperoxide.

$\stackrel{\div}{*}<.001$ versus groups 2,3 , and 4 .

child. $5,15,16,18,22-24$ After a hypoxic-ischemic stress, hearts protected with unmodified blood cardioplegic solution sustained a significant oxygen-derived free radical-mediated reperfusion injury resulting in vascular dysfunction (elevated CVR), mitochondrial damage, and depressed myocardial function. In contrast, oxygen-derived free radical production was equally reduced if the cardioplegic solution was enriched with L-arginine or $\mathrm{PGE}_{1}$ or was passed through a WBC fil- ter. By avoiding the reperfusion injury, mitochondrial function was preserved (ATP/ADP ratio), which allowed energy levels to be replenished, resulting in increased oxygen uptake during cardioplegic induction, as well as complete functional recovery. Compared with L-arginine and $\mathrm{PGE}_{1}$, use of leukocyte filtration resulted in similar levels of oxygen-derived free radical production, myeloperoxidase activity, and metabolic and functional recovery. This implies that 
WBCs are responsible for the generation of the majority of oxygen-derived free radicals during reperfusion and that most of the beneficial effects of L-arginine and prostaglandins are due to inhibition of WBC adherence. We cannot prove, however, that all these modalities work via an identical pathway, because we did not specifically examine the mechanism of action with each intervention. It is possible that $\mathrm{L}$-arginine and $\mathrm{PGE}_{1}$ limit the reperfusion injury via a non-WBCdependent mechanism or by a combination of effects, since these agents also prevent platelet adherence and induce vasodilatation. However, because one of the primary effects of L-arginine (nitric oxide) and $\mathrm{PGE}_{1}$ is to prevent adherence of activated WBCs, this mechanism is probably responsible for a substantial portion of their beneficial effects.

CVR was measured with each cardioplegic infusion to determine whether any of the beneficial effects of Larginine or $\mathrm{PGE}_{1}$ were due to their ability to promote vasodilatation. ${ }^{1-3,7,12,21,25}$ After an ischemic stress, the coronary vasculature should be vasodilated. The higher CVR with unmodified blood cardioplegic solution (group 1) therefore implies vascular dysfunction resulting from endothelial cell injury. Conversely, the lower CVR with L-arginine, prostaglandins, or WBC filtration implies avoidance of this injury with preservation of vascular function. Because a WBC filter does not cause vasodilatation, the similar CVR in these 3 groups suggests that L-arginine and prostaglandins are acting primarily to preserve vascular function through inhibition of WBCs, and not as vasodilators. This hypothesis remains speculative because specific tests of vascular endothelial cell function were not performed after bypass. However, elevated CVR most likely indicates vascular damage since it correlates with increased production of oxygen-derived free radicals, mitochondrial damage, and poor functional recovery.

We cannot determine whether combining a WBC filter with a pharmacologic agent (L-arginine and prostaglandins) would further improve results, because hearts receiving $\mathrm{L}$-arginine, $\mathrm{PGE}_{1}$, or leukodepletion recovered completely. However, because of differences between these modalities, it is possible that they should be used together. For instance, L-arginine is not as effective when given cold, whereas WBC filters are relatively unaffected by temperature. The optimal dosages of L-arginine and prostaglandins are unknown in human beings under various pathologic conditions; therefore, if a low dose is used for safety, these agents may not be as effective as they were in this study. Some WBCs escape filtration, and leukocyte filters become less efficient with greater volumes or higher flow rates.
A chemical (pharmacologic) blocker may help prevent adhesion of these unfiltered leukocytes. L-Arginine and prostaglandins also promote vasodilation, as well as limiting platelet adherence. 1,3,7,13,14,21,25 Increased vascular resistance may limit cardioplegic distribution, and platelet deposition results in capillary plugging with release of potent vasocontrictors. In contrast, the Pall BC-1 leukocyte-depleting filter only slightly reduces platelet counts. The aforementioned factors probably explain why Hiramatsu and associates ${ }^{2}$ demonstrated improvement when WBC filtration and L-arginine were combined. Using a pharmaceutical agent along with a WBC filter may therefore improve myocardial protection in cyanotic children. However, because of potential hazards with L-arginine, we would recommend using prostaglandins, especially since they have a similar effect.

In conclusion, L-arginine, $\mathrm{PGE}_{1}$, and leukocyte filtration all substantially and equally improve myocardial protection by limiting a WBC-mediated injury, which reduces oxygen-derived free radical production and helps to restore endothelial, metabolic, and functional recovery. Because pediatric patients are more sensitive to surgical ischemia, as well as being prone to postbypass myocardial dysfunction, surgeons should consider incorporating these modalities into their protective strategies.

\section{REFERENCES}

1. Mizuno A, Baretti R, Buckberg GD, Young H, Vinten-Johansen J, $\mathrm{Ma} \mathrm{X}$, et al. Endothelial stunning and myocyte recovery after reperfusion of jeopardized muscle: a role of L-arginine blood cardioplegia. J Thorac Cardiovasc Surg 1997;113:379-89.

2. Hiramatsu T, Forbess J, Miura T, Nomura F, Mayer Jr JE. Additive effects of L-arginine infusion and leukocyte depletion on recovery after hypothermic ischemia in neonatal lamb hearts. $\mathrm{J}$ Thorac Cardiovasc Surg 1995;110:172-9.

3. Sato H, Zhao Z, McGee DS, Williams MW, Hammon JW Jr, Vinten-Johansen J. Supplemental L-arginine during cardioplegic arrest and reperfusion avoids regional postischemic injury. J Thorac and Cardiovasc Surg 1995;110:302-14.

4. Carrier M, Khalil A, Tourigny A, Solymoss B, Pelletier L. Effect of L-arginine on metabolic recovery of the ischemic myocardium. Ann Thorac Surg 1996;61:1651-7.

5. Kronon M, Allen BS, Halldorsson A, Rahman SK, Wang T, Ilbawi M. Dose dependency of L-arginine in neonatal myocardial protection: the nitric oxide paradox. J Thorac Cardiovasc Surg 1999;118:655-64.

6. Matheis G, Sherman P, Buckberg G, Haybron D, Young H, Ignarro L. Role of L-arginine-nitric oxide pathway in myocardial reoxygenation injury. Am J Physiol 1992;262:H616-20.

7. Boyle EM Jr, Pohlman TH, Cornejo CJ, Verrier ED. Ischemiareperfusion injury. Ann Thorac Surg 1997;64:S24-30.

8. Morita K, Ihnken K, Buckberg GD, Sherman MP, Young HH. Studies of hypoxemic/reoxygenation injury: without aortic 
clamping. V. Role of the L-arginine-nitric oxide pathway. J Thorac Cardiovasc Surg 1995;110:1200-11.

9. Byrne JG, Appleyard RF, Lee CC, Couper GS, Scholl FG, Laurence RG, et al. Controlled reperfusion of the regionally ischemic myocardium with leukocyte-depleted blood reduces stunning, the no-reflow phenomenon, and infarct size. J Thorac Cardiovasc Surg 1992;103:66-72.

10. Kraemer R, Mullane K. Neutrophils delay functional recovery of the post hypoxic heart of the rabbit. J Pharmacol Exp Ther 1989; 251:620-6.

11. Halldorsson A, Kronon M, Allen BS, Bolling KS, Wang T, Rahman SK, et al. Controlled reperfusion after lung ischemia: implications for improved function after lung transplantation. J Thorac Cardiovasc Surg 1998;115:415-25.

12. Verrier ED, Boyle EM Jr. Endothelial cell injury in cardiovascular surgery: an overview. Ann Thorac Surg 1997;64:S2-8.

13. Smalling R, Feld S, Ramanna N, Amirian J, Felli P, Vaughn W, et al. Infarct salvage with liposomal prostaglandin $E_{1}$ administered by intravenous bolus immediately before reperfusion in a canine infarction-reperfusion model. Circulation 1995;92:943.

14. Feng J, Wu G, Liu R, Tang S. Prostaglandin $\mathrm{E}_{1}\left(\mathrm{PGE}_{1}\right)$ reduces cardiac-derived TXA 2 release in ischemic arrest in isolated working rat heart. Int J Cardiol 1996;55:265-70.

15. Bolling KS, Kronon M, Allen BS, Ramon S, Wang T, Hartz R, et al. Myocardial protection in normal and hypoxically stressed neonatal hearts: the superiority of hypocalcemic versus normocalcemic blood cardioplegia. J Thorac Cardiovasc Surg 1996;112:1193-201.

16. Bolling KS, Kronon M, Allen BS, Wang T, Ramon S, Feinberg H. Myocardial protection in normal and hypoxically stressed neonatal hearts: the superiority of blood versus crystalloid cardioplegia. J Thorac Cardiovasc Surg 1997;113:994-1005.

17. Hanafy HM, Allen BS, Winkelmann JM, Ham JW, Osimani D, Hartz RS. Warm blood cardioplegic induction: an underused modality. Ann Thorac Surg 1995;58:1589-94.

18. Bolling KS, Halldorsson A, Allen BS, Rahman SK, Wang T, Kronon M, et al. Prevention of the hypoxic/reoxygenation injury with the use of a leukocyte-depleting filter. J Thorac Cardiovasc Surg 1997;113:1081-90.

19. Allen BS, Rahman SK, Ilbawi M, Feinberg H, Bolling KS, Kronon M. The detrimental effects of cardiopulmonary bypass in cyanotic infants: preventing the reoxygenation injury. Ann Thorac Surg 1997;64:1381-8.

20. Schulz R, Wambolt R. Inhibition of nitric oxide synthesis protects the isolated working rabbit heart from ischemia-reperfusion injury. Cardiovasc Res 1995;30:432-9.

21. Anonymous. Prostin VR solution: medical information. Pharmacia and Upjohn, Kalamazoo (MI). 1998.

22. Del Nido PJ, Mickle DAG, Wilson GJ, Benson LN, Weisel RD, Coles JG, et al. Inadequate myocardial protection with cold cardioplegic arrest during repair of tetralogy of Fallot. J Thorac Cardiovasc Surg 1988;95:223-9.

23. Silverman N, Kohler J, Levitsky S, Pavel D, Fang R, Feinberg H. Chronic hypoxemia depresses global ventricular function and predisposes to depletion of high energy phosphates during cardioplegic arrest: implications for surgical repair of cyanotic congenital heart defects. Ann Thorac Surg 1984;37:304-8.

24. Graham TP Jr, Erath HG Jr, Buckspan GS, Fisher RD. Myocardial anaerobic metabolism during isoprenaline infusion in a cyanotic animal model: possible cause of myocardial dysfunction in cyanotic congenital heart disease. Cardiovasc Res 1979; 13:401-6.
25. Campbell W, Halashka P. Lipid-derived autacoids. In: Hardman J, Limbird L, editors. Goodman and Gilman's the pharmacological basis of therapeutics. 9th ed. New York: McGraw-Hill; 1996. p. 601-16.

\section{Discussion}

Dr Bradley Hofer (Seattle, Wash). Dr Allen, you and your coauthors are to be congratulated on a well-designed study in a model of neonatal, hypoxic, ischemic reperfusion injury. I presume this model is meant to simulate cyanotic infants who are then subjected to ischemic reperfusion with subsequent hyperoxic cardiopulmonary bypass.

You used a model of combined subacute hypoxia followed by ischemic stress in piglets. Do you believe these results are applicable to adult mature myocardium and endothelium?

Dr Allen. To make the heart more sensitive to differences in myocardial protection, we subjected piglets to an ischemic and hypoxic stress. We used the combination of ischemia and hypoxia because cyanotic infants often have depressed myocardial ATP levels owing to episodes of ischemia that occur during times of stress. Although our model might not completely simulate the condition of the cyanotic infant, it allows us to test different cardioplegia strategies in vulnerable hearts. This is no different from simulating an ischemic stress in adult studies by crossclamping the aorta. This may not exactly simulate chronic angina, but it subjects the adult heart to a clinically relevant stress. Investigating stressed hearts is extremely important in both adult and pediatric studies, because they are the most difficult to protect. It is my belief that the principles of this study are applicable to both pediatric and adult patients. However, without a definitive investigation, I cannot be certain.

Dr Hofer. I was impressed that the effects on both the CVR and myocardial oxygen consumption are immediate; 1 minute after your induction dose you see an amelioration of these in all 3 groups. This is understandable in the WBC filter groups, since they theoretically have been treated the entire course, before their induction therapy. However, how can you explain this happening so rapidly in the $\mathrm{PGE}_{1}$ and the nitric oxide groups? Does this imply that a very small dose at the beginning of induction is sufficient, as opposed to a longer infusion?

Dr Allen. The initial reintroduction of blood caused a reperfusion injury in the unmodified group, resulting in an increase in both oxygen-derived free radical production and CVR. Conversely, this injury was avoided (low oxygen radical formation) if the cardioplegic solution was enriched with $\mathrm{PGE}_{1}$, L-arginine, or leukodepleted, improving functional recovery. Because oxygen-derived free radical formation and CVR are decreased during cardioplegic induction with Larginine, $\mathrm{PGE}_{1}$, and leukodepletion, it is possible these agents are not required after the initial period of reperfusion, or during subsequent cardioplegic infusions. However, previous studies suggest they need to be delivered for several minutes to obtain maximal benefit. Furthermore, because these modalities help prevent the reperfusion injury, and hearts are 
ischemic between cardioplegic infusions, they are probably beneficial during each cardioplegic infusion. None of the groups were pretreated. A WBC filter was used only to filter leukocytes in the cardioplegic solution. Therefore, the only difference between groups was the cardioplegic solution. The $\mathrm{PGE}_{1}$ concentration was relatively low and equivalent to a systemic dose of 0.2 to $0.4 \mu \mathrm{g} \cdot \mathrm{kg}^{-1} \cdot \mathrm{min}^{-1}$, which is one fifth of what is often used to keep a patent ductus open.

Dr Hofer. Since you are concerned that a higher dose of Larginine is injurious, would an experiment in which you apply only one dose, as opposed to continuing through the whole infusion, theoretically remove those injurious side effects?

Dr Allen. No, I do not believe so. In the previous study (see page 655) we found a marked increase in oxygen radical formation and CVR during cardioplegic induction if the concentration of L-arginine was increased. Therefore the detrimental effects of L-arginine seem to be dependent on the concentration, not the total dose.

Dr Hofer. Would you expect the exact same results if you were to give adenosine as a vasodilator or if you were to block adhesion by another mechanism?

Dr Allen. Yes, I believe the same results could be expected. There are dozens of prostaglandins as well as prostacyclin and adenosine, all of which seem to have the similar actions of limiting WBC and platelet adherence and inducing vasodilatation. We chose $\mathrm{PGE}_{1}$ because it is routinely used in infants, it may be one of the mediators by which nitric oxide works, and several studies have documented its effectiveness in reducing reperfusion injury after ischemia. However, we probably would have had similar results had we used adenosine, prostacyclin, or a variety of other prostaglandins.

Dr Edward Verrier (Seattle, Wash). I am a bit concerned about the conclusions. A number of other cells are involved with hypoxic injuries, including endothelial cells and platelets. Therefore, to say your observations are only mediated by WBCs may be true but unrelated. One simple experiment that could be done would be to add the different components into the same solution and see whether the results change. For instance, one could use either prostaglandin or the WBC filter and see whether the factors are additive in some fashion. The fact that you get the same level with each intervention does not necessarily mean that they are mediated by exactly the same mechanism.

Dr Allen. You are probably right. In addition to inhibiting WBCs, prostaglandins block platelet adherence and induce vasodilatation. These effects are also important in preventing cellular injury after ischemia. Dr Mayer and associates recently demonstrated that using L-arginine and WBC filters together improved myocardial protection much more effectively than using either modality separately. It may be that our model was not severe enough to allow us to demonstrate the added benefits of vasodilatation or decreased platelet adherence. However, the present study does suggest that a major beneficial effect of L-arginine and prostaglandin is due to inhibition of WBC-mediated injury. Platelets and vascular dysfunction definitely play a role in the pathogenesis of the reperfusion injury, and modalities that also block these adverse effects may be superior. We therefore believe that WBC filters and chemical blockers, such as $\mathrm{PGE}_{1}$, should probably be used together.

Dr Verrier. This type of hypoxic stress induces endothelial cells, for instance, to up-regulate a huge number of inflammatory mediators. They do not even get expressed out until 4 hours. Thus the results that you report here are very early-phase results and may be significantly different from what would be seen at 6 hours (in terms of the return of function).

Dr Allen. There may be an up-regulation of inflammatory mediators that will increase the inflammatory response several hours later. Using L-arginine, $\mathrm{PGE}_{1}$, or leukodepletion, however, prevented the initial production of free radicals during reperfusion. By limiting the reperfusion injury, inflammatory up-regulation should at least be partially suppressed. Furthermore, limiting the reperfusion injury may also allow the cell to be less susceptible to any inflammatory mediators several hours later. 